Published as: Bekkers, V.J.J.M., Information and commuication technology and the redefinition of the functional and normative boundaries of government, in: Van Heffen, O. et. al. (eds.), Governance in modern society, Kluwer Academic Publishers, Dordrecht, 2000, pp. 257-278.

\title{
INFORMATION AND COMMUNICATION TECHNOLOGY AND THE REDEFINTION OF THE FUNCTIONAL AND NORMATIVE BOUNDARIES OF GOVERNMENT
}

Prof. dr V.J.J.M. Bekkers [1]

\section{Introduction}

In 1996 Dutch parliament executed a law (the so-called Koppelingswet), which enables a large number of (quasi-)public and private organizations, like the immigrant office, the tax administration, social security agencies, hospitals and notary's offices, to exchange electronically data regarding the permit of residency of foreigners and immigrants. The goal of this coupling operation is the reduction of fraud and abuse of services by people who have no permit of residency. The information resources between the immigrant offices and other organizations are being shared and integrated, which leads tot changes in the organizational boundaries of these organizations; to some extent they begin to blur.

In the literature about public organizations not much attention is given to the question whether information and communication technology (ICT), especially the use of network technology, does change the nature of organizational boundaries. Posing this question is important, because the blurring of organization boundaries in the public sector could have profound implications for the assumptions and doctrines which underlie the organization and functioning of the government. The idea of jurisdiction, which plays an important role in the Weberian theory of bureaucracy but also in political theories about federalism, separation of powers and 'checks and balances', is challenged through computerization. Jurisdiction can be described as the exclusive authority of an actor as a unified entity to determine rights and obligations of citizens in a task domain with (a certain degree of ) discretion for which this actor is legally and politically accountable. In this chapter I will demonstrate that the use of ICT will lead to changes in the boundaries of government organizations which will also affect the jurisdictions of government organizations.

In this contribution I develop a conceptual framework which helps me to investigate the question, of whether the nature of organizational boundaries is changing and in which direction boundaries are shifting because of ICT. The idea of organizational boundaries is a fuzzy concept, which becomes even fuzzier if we accept that our understanding of organizations is multi-interpretable (Morgan, 1986). In section two I will define organizational boundaries from a legal and rational perspective. From this point of view boundaries have a normative nature. However, this is just one way of defining boundaries. In section three other theoretical perspectives will be presented, which define the boundaries of organizations in a different way. All these definitions have one striking resemblance. They refer to the change-over between critical uncertainty and ambiguity of the outside-world and uncertainty which can be controlled and managed in the organization itself (section four). At the same time I will conclude that organizations become more (inter) dependent from each other, which very often leads to an increase in the exchange of information. ICT facilitate these exchange processes. In section five a number of characteristics of ICT are sketched, which can influence the definition of organizational boundaries and jurisdictions. In section six some scenarios are sketched which show us how the boundaries of (semi-) public organizations are changing through the application of ICT in order to realize certain policy goals. The scenarios are constructed on empirical research (Bekkers, 1998). In section seven I will show how informatization leads to a re-definition of organizational boundaries and jurisdictions in public administration, which asks for a new political theory regarding the role of government in the information age. Politics in the information age will be information and technology politics, which involves other values and norms. 


\section{Organizational jurisdictions and legal boundaries}

In European public administration the term jurisdiction is traditionally reserved for the competencies of judges and courts to administer justice in a certain geographical or functional domain. Every region has its own court and for specific areas there are special judges, for instance with respect to tax matters. However, the notion of jurisdiction can also be used to describe the competencies and tasks of government organizations. For instance, in the Netherlands municipalities have the competency to lend social assistance to people who lack income, or to give people a license to build a house. More generally, public administration can be seen as a collection of organizational competencies and jurisdictions. Between these government organizations, but also between public and private organizations, information is being exchanged in order to fulfil their tasks and to accomplish their policy goals. Jurisdictions are embedded in an network of information exchange patterns and relations. Very often ICT is used to facilitate these exchange relations.

An organizational jurisdiction I describe as the exclusive authority of an actor as a unified entity to determine rights and obligations of citizens in a task domain with (a certain degree of) discretion for which this actor is legally and politically accountable (Bekkers, 1998). The board of the mayor and aldermen in a municipality (a unified entity) and the executing local social service agency has the exclusive authority to give citizens who live within the territory of the municipality, under specific conditions social benefits. Citizens have certain legal rights and obligations to receive them, while a municipality has also legal rights and obligations to render them. A municipality has the right, within a framework, to develop and implement its own social aids program. The board of layman is politically accountable for this program and the decisions based on it, to the council of the municipality.

Two ideas lay behind this notion of organizational jurisdiction. The first idea is that government should be seen as a rational organization. After all, government bureaucracies should be seen as the expression of functional rationality as Weber once described it. The second idea is that government organizations should function according to some principles of the 'Rechtstaat'.

\section{The rational model of organization}

The rational approach to organization stresses that an organization is a set of means and people to achieve a number of specific goals in an efficient and effective way (Scott, 1992). These goals can only be accomplished if these means and people are rationally ordered. The emphasis lies on the structure of the organization, which resembles the image of a machine and a pyramid. Mintzberg (1979:2) defines the organization structure as "the sum total of the ways in which labor is divided into distinct tasks and then its coordination is achieved among these tasks”.

How are the boundaries of organization conceived in the rational model? Decisive is the goal of the organization; a goal which is further operationalized and translated in sub-goals and corresponding tasks and competencies. This aspect is especially important for government organizations, because their tasks and competencies are laid down in all kinds of laws and regulations, which define the organizational jurisdiction of a government organization. If these tasks and competencies are changing, or become entangled with those of other organizations, boundaries and jurisdictions are changing.

Formalization is another relevant factor in determining the boundaries of government organizations. Formalization tries to make behavior of people predictable by reducing uncertainty, variety and subjectivity. The boundaries of an organization become visible in situations where the behavior of people within the organization has become uncertain and capricious. Uncertainty can be reduced by the further rationalization of the organization, by using new and more sophisticated ways of formalizing, standardizing and controlling organizational behavior (Scott, 1992).

Rationality is also a factor to be mentioned. Simon (1956) questioned the rationality of organizational decision-making by introducing the concept of bounded rationality. Organizational boundaries refer to the limited cognitive capacity of individuals to make rational decisions. They are informational boundaries, determined by the limited information-processing (cognitive) capacity of an organization, that can be enlarged by using ICT. 
Government organizations are embedded in the 'Rechtstaat'. What are the principles which lay behind this idea and how do they influence the functioning of government organizations and the definition of jurisdictions? Typical for the 'Rechtstaat' is that government action which influences and very often restricts the behavior of citizens, should be based on the law. It is the law which allocates the competencies, tasks and responsibilities among government organizations and it is the law which defines the extent and the contents of these competencies, tasks and responsibilities.

We can discern a number of characteristics which are related to the attribution of legal competencies. First, there is the contents of the legal task and competence. Secondly, there is the territorial and/or functional domain of the competency. Thirdly, there is the degree of discretion a government organization has in fulfilling its tasks. Does the law describe in detail how a task should be executed, what is the degree of formalization, and to which extent is the organization free in the execution of this task?

The degree of formalization of the content of a task and the territorial and/or functional domain define to some extent the legal boundaries of government organizations. They become even more important if we look at another characteristic of the 'Rechtstaat', in which well defined tasks and competencies are seen as a guarantee to prevent unwanted concentration of power in the hands of one government organization. Doctrines like the 'trias politica', the division of powers and 'checks and balances' are important principles which define the normative boundaries of government organizations and the patterns of accountability which accompany them.

Another relevant characteristic of the 'Rechtstaat' is the notion of the constitutional rights of citizens. They are seen as a safeguard against the abuse of power of government organizations such as the right of privacy. These rights also define the jurisdiction of government organizations. The last characteristic of the 'Rechtstaat' is the fact that citizens could appeal to an independent judge or court (Burkens et al., 1997).

In this section I have described the factors which influence the definition of organizational boundaries and jurisdictions. These boundaries have a normative nature. They refer to ideas of the 'Rechtstaat' and they refer to the specific goals which a government organizations should realize and which are laid down in a policy program or in the law. However, the meaning of organizational boundaries cannot only be understood from a rational and legal. Other perspectives should also be taken into consideration.

\section{Other organizational models and other organizational boundaries}

If one tries to investigate the question if organizational boundaries are changing through ICT, one has to broaden its scope. An organization can be conceptualized in many ways, which also influences the definition of these boundaries (Haas and Drabeck, 1973; Morgan, 1986). Paying attention to these other boundaries is important, because there is interaction between the legal and rational boundaries of the organization and other organizational boundaries. Legal boundaries are important, but they are not the only relevant ones.

\section{The cultural model of organization}

An organization is a community in which people work and live. One of the characteristics of a community is that it has a culture, which can be described in terms of 'taken for granted assumptions', values and norms, rituals, heroes, legends and communication patterns (Frissen, 1989). Norms, values, rites, rituals, heroes, myths, legends etc. reduce uncertainty and create safety and stability. They give meaning to the life of the members of the organization. Organizational boundaries symbolize the distinction between the well-known and sheltered world inside -inclusion- and the relatively unknown world outside the organization - exclusion (Easton, 1965; Katz and Kahn, 1966). “A boundary line stands rather as a symbol or as a spatial embodiment of the criteria of inclusion-exclusion with respect to a system. It is a summary way of referring phenomenally to what we have included in or left out of a system" (Easton, 1965:66). Coding systems make people aware that he/she is leaving or entering the organization. Certain symbols (e.g. the uniform of the porter, insigna like badges), specific languages or grammar (e.g. the way a stranger is approached at the reception or by the telephone operator), rituals (like procedures for checking in and out) are manifestations of organizational boundaries ands 
organizational jurisdictions (Katz and Kahn, 1966). These manifestations play an important role in the communication of people in the organization and between organizations (Weick, 1969). As Willke (1991:30) puts it: "Intersubjectiv geteilter Sinn grenzt systemspezifisch ab, was als sinnvoll und was als sinnlos zu gelten hat”. Boundaries are not only (re-)defined in the communication between people, but they also influence the meaningfulness of communication between people.

\section{The political model of organization}

In the political perspective an organization is seen as an arena. This arena consists of a conglomerate of parties with conflicting, but also with mutual interests. Parties try to protect their interests by using power. They develop strategies and tactics to mobilize and employ different power resources, like formal authority, financial funds, knowledge and expertise, information, relations, image etc. However, these resources are not always concentrated in the hands of just one party. They are distributed among several parties, which leads to all kinds of patterns of (inter)dependency and exchange. This creates uncertainty and controlling uncertainty opens the door to the employment of power (Crozier and Friedberg, 1980; Pfeffer, 1981; Morgan, 1986).

The idea of controlling uncertainty and dependency as important power resources is important for establishing an insight in the nature of organizational boundaries. In the literature attention is paid to those people or units which we are called 'gatekeepers'. They are situated on the boundaries of the organization and they fulfil or occupy 'boundary spanning functions or positions' (Adams, 1980). Due to the differentiation and specialization of tasks, there are, within an organization, numerous subenvironments and corresponding gatekeepers and boundary spanning activities.

Characteristic for gatekeepers is that they open or close channels of communication, thereby filtering, summarizing, analyzing information and thus shaping knowledge with a view of the world that favors their interests (Morgan, 1986). They control not only information and knowledge but also the distribution of it, and thus employ power by influencing the perceptions and attitudes of those parties who are dependent on it (Pfeffer, 1981). According to Crozier and Friedberg (1980 the (re)definition of organizational boundaries is an ongoing political game which involves parties within and outside the organization.

\section{The open system's model of organization}

In the system's approach the organization is seen as a set of loosely coupled, but interrelated elements or subsystems which are aimed at the achievement of certain goals. But, the ultimate goal is the organization's survival within a specific environment. Organizations are seen as natural and open systems which are connected to an environment through all kinds of input and output processes. An organization draws its resources from the environment (input), and transforms these resources (the throughput) into goods or services (output). An organization is capable of surviving if it is able to attract those inputs necessary to survive and to produce those outputs which can be disposed of (Scott, 1992).

The introduction of an environment means that somewhere there is a change-over between the system and the environment. However, this change-over is not clear. Boundaries refer to the transactions i.e. interactions between a system and the environment. Transactions with the environment imply discontinuity and are therefore a source of uncertainty. On the one hand these transactions are a threat to the stability of the system, on the other hand many of these transactions are vital for the survival of the system (Katz and Kahn, 1966; Miller and Rice, 1967).

The idea of the 'organizational domain' could bring some relief in order to operationalize the empty concept of 'the environment'. The domain of the organization consists of the claims it makes on products or services provided and populations served. The claims immediately relate it to a number of other organizations, such as suppliers, customers, competitors and regulatory groups like governments, that affect its behavior and outcomes (Thompson, 1967). Organizational boundaries refer to the degree of consensus among the parties within an organizational domain about the properness of their claims (Levine \& White, 1961). "Domain consensus defines a set of expectations both for the members of an organization and for the others with whom they interact about what the organization will and will not do" (Thompson, 1967:29). The result of this consensus is that it stabilizes the exchange relations between organizations. Zucker et al (1995) see the production of trust - as a result of bargaining and communication in order to reduce uncertainty - as an necessary condition for establishing domain 
consensus. An organizational jurisdiction can be seen as the expression of domain consensus and trust with respect to the ways an public organization exercises its legal competencies. They influence the legitimacy of an government organization.

The open's systems model of organization extended: the interorganizational relations

The definition of organizational boundaries is not only influenced by the legal domain of an organization or its jurisdiction. The exchange relations between organization also play an important role (Levine \& White, 1961; Evan, 1966; Warren, 1966; Thompson, 1967; Benson, 1978; Pfeffer \& Salancik, 1978; Aldrich, 1979; Van de Ven et al, 1979). Government organization are embedded in a network of information exchange relations that constitute a policy sector. The number and contents of exchange relations also influence the definition of organizational boundaries.

The fact that organizations are (inter)dependent on each other, has important implications for their autonomy. Pfeffer and Salancik (1978) elaborate this idea. An organization is only capable of surviving, if it can reduce its dependency on resources which are vital or critical for its functioning and existence. However, the problem is that the access, distribution and availability of these resources are controlled by other organizations. The resulting dependency creates uncertainty. Organizations are not fully in control of themselves. There is some external control and power over them. Therefore Pfeffer and Salancik (1978:32) conclude that the boundary is "where the discretion of the organization to control an activity is less than the discretion of another organization or individual to control that activity". In other words, "the organization ends where its discretion ends and another's begins" (Pfeffer and Salancik, 1978:32). Discretion refers to capacity to control external resources. However, determining exactly where the discretion of an organization ends and another's begins, is rather ambiguous.

Organizations develop several strategies to reduce external uncertainty and dependence. By redefining their external relations they are capable of creating or enacting their own environment. The boundaries of the organization shift, for instance through mergers, interlocking directorates, joint ventures and other strategic alliances. They also shift, if an organization can determine the assumptions and premises of the decisions of other (dependent) organizations (Pfeffer \& Salancik, 1978).

In the exchange model of organizations (Levine and White, 1961; Evan, 1966; Warren, 1967; Benson, 1978) interdependency is related to the need for coordination and concerted action. Much attention is given to processes of communication, negotiation, competition and exchange. These processes move between two needs: the necessity to cooperate on the one hand and the desire to maintain the organization's autonomy i.e. to secure the organizational boundaries on the other hand. Negotiation and communication processes are important in creating a balance between these two needs and in establishing a degree of consensus about the nature of the perceived dependency and the conditions under which exchange of resources could take place.

In studies about interorganizational relations attention is not only given to the definition of these relations, but also to their structure. Several dimensions can be discerned (Marret, 1971; Van de Ven et al, 1979; Aldrich, 1979). First, interorganizational relations can be standardized and formalized, for instance in a contract or public regulation. For instance, is an exchange relation mandatory, and are specific procedures developed to exchange resources like information? Secondly, the intensity of the relationship tells us something about the degree of (inter)dependency. Intensity refers to the amount of resources exchanged as well as the frequency of exchange: it is this ad hoc or permanent? Another dimension is the degree of reciprocity. Is there symmetric or asymmetric dependency? Does the exchange of resources lead to a situation in which both parties can benefit? And, is there consensus about the nature of, and the conditions under which an exchange can take place? For instance, organizational boundaries become more important if an organization has the obligation to exchange certain resources like information or money which affects the organizational autonomy. And, the more these exchange relations are being standardized and intensified, then organizations become more entangled and boundaries become more permeable. This is very often the case in public policy networks and in situations in which certain activities are outsourced or subcontracted.

These relations can become institutionalized and all kinds of stable patterns and forms of exchange and negotiation can emerge. Warren (1967) has paid special attention to these forms of cooperation. The more exchange relations become permanent and institutionalized, the higher the degree of 
interdependency, the more the boundaries of organizations are being put under pressure.

\section{About the nature of organizational boundaries}

The previous observations show that thé organization as such does not exist. Every model defines the boundaries of an organization in a different way. An organization is at the same time rational and legally oriented, culturally embedded, subjected to a struggle for power, and engaged in all kinds of interactions with groups in the environment. Our notion of organizational boundaries is therefore relative.

However, a closer inspection reveals that these models do have something in common. Organizational boundaries refer to the management of critical uncertainty and ambiguity, but every model highlights other aspects about the nature and causes of uncertainty and ambiguity. Critical, because this kind of uncertainty is vital for the stability and smooth functioning of the organization.

The notion that thé organizational boundaries do not exist, also has important methodological implications. Some authors (Easton, 1965; Haas and Drabek, 1973; Pfeffer and Salancik, 1978) make the observation that organizational boundaries are an analytical construct. "Organizational boundaries may be viewed as constructs invented by analysts who will draw them at different points, depending upon their theoretical interests" (Haas and Drabeck, 1973: 20). However, these constructs refer to empirical manifestations, but what are they? Haas and Drabeck (1973) and Pfeffer and Salancik (1978) focus their attention on the interactions of actors (groups, individuals, units). Typical for these interactions is that they are accompanied by uncertainty, which could have different (e.g. cultural and political) meanings for the actors involved. The boundaries of an organization are defined in the interactions between members and groups within the organization and between members and groups outside the organization.

However, there is another relevant observation. Boundaries differ according to the position of the actor involved. The boundaries a minister defines as meaningful differ from those of the director of a policy unit or the department's accountant. Organizational boundaries are also a normative construction (Haas and Drabek, 1973; Willke, 1992). The actor's position or role defines the things which he sees as crucial to the discretion of the organization and which can or should be influenced. In the case of a government organization the normative nature of boundaries becomes even more important, because they are formulated in the law and they are embedded in the 'Rechtstaat'.

\section{Interorganizational information processing}

Relations and transactions between organizations often involve the exchange of information. ICT can facilitate these exchange processes. If we want to understand what impact these technologies have on the functioning of organizations and the changing nature of organizational boundaries, attention should be given to the characteristics of ICT (Bekkers, 1993; Tapscott, 1995; Frissen, 1996, Martin, 1996). However, the characteristics of ICT and their translation into specific ICT-applications should not be seen as neutral forces. They are linked to certain policy goals which an organization would like to accomplish and the position and interests an organization tries to protect within a policy sector or policy network (Kling, 1987)

\section{Characteristics of ICT}

Twenty years ago, information technology was primarily a technology which was used for calculation purposes and to undertake massive, standardized transactions. Automation was the key word. During the last ten years we see that information technology has also become communication technology. The development of network technologies (EDI, Inter- and intranet), the coupling of data bases, telematics, group ware and all kinds of search systems have stressed the importance of other characteristics, besides calculation.

First, there is the communication potential. The necessity of presence availability, in terms of sharing the same time, place and location, is not an essential condition for effective communication anymore. Secondly, network technologies offers new possibilities for establishing all kinds of links between people and organizations. They become 'wired' and the quality and quantity of their 
interactions increases. These linkages become even more meaningful if we look at the increased digital integration or interconnectivity between speech, images and sounds and the corresponding infrastructures and technologies (Negroponte, 1994; De Kerckhove, 1996). Thirdly, ICT enhances the transparency and access of organizations. The surrounding walls are falling down. For instance, the information systems of libraries, laboratories and government agencies can be consulted through the Internet, while intranets and groupware devices also make it possible to share organization-wide information resources. Also, computers systems and databases are being coupled by using network technology and data is being matched. It becomes easier to detect relevant trends and development in policy fields, policy target groups, but also the outcomes of policy organizations can be made more visible. Fourthly, transparency opens the door for more sophisticated ways of control and surveillance. Monitoring systems are deployed in order to watch the results of those policy units which implement certain policy programs. But also the coupling of databases and the use of 'data mining' techniques and data profiles enable government organizations to reconstruct, follow and control the behavior of (groups of) citizens, for instance in order to detect fraud of abuse of social security services. Fourthly, there is virtual reality. In and by network technology new, virtual realities are shaped, which stand apart from the real world in which people live, work, learn, shop and produce. It is the world of the virtual communities, cyber corporations and electronic markets. Everything which occurs in the real world also happens in the cyberspace, but do boundaries exist in cyberspace, if everything is connected?

These characteristics in combination with the interests which are at stake and goals an organizations wants to realize, influences the definition of organizational boundaries. Information processing, communication and interaction is being facilitated through these new technologies. The wiring of organizations means that those organizations which participate in a network loose some of their autonomy. For instance, they become more transparent, thereby enhancing the possibility of external or interorganizational control, which redefines the boundaries of the organization. For instance, how permeable should a municipality be if it implements a policy program which is formulated by the Department of Social Affairs? Moreover the establishment of a network creates new interdependencies between organizations which very often can be seen as the expression of trust or power. But also, working and planning processes between separate organizations can better integrated. This integration becomes more crucial if there are on-line and real time connections.

\section{Characteristics of interorganizational information processing}

Not only do these characteristics of ICT affect organizational boundaries, but also other factors, which are related to the broader concept of interorganizational information processing, should be considered. First, there is the direction of information processing. Is this one-way processing, for instance a government agency which is mandatorily obliged to give information to another agency or ministry? Or, do separate organizations share the same information systems and data bases? Another factor is the intensity of interorganizational information processing. Do organizations exchange data permanently or on an ad hoc basis? For instance, the structural exchange of data could stimulate organizations to develop a common infrastructure and common data definitions. Another factor relates to the way data is transferred and processed. Is this for instance in a batch-mode or on-line and in real time? Is the data exchanged according to a format, or is the data unstructured? There is also the nature of the information to be processed? Does it concern technical and operational information which relates to the working processes within two or more organizations (e.g. name and address information), or does it concern allocative information (e.g. budgeting, planning and control information), or does it regard strategic information (e.g. market information). Or is it privacy sensitive information? The latter refers to the techniques of interorganizational information processing. The exchange of information through structured communication networks like EDI has other implications for the blurring of organizational boundaries than open communication networks like the Internet.

\section{Re-defining organizational boundaries}

Research regarding the question if and how the boundaries of organizations in the public sector change through ICT has led to the inductive development of a number of scenarios (Bekkers, 1998). In 
general two types of scenarios are discerned. The first number of scenarios elaborates on the observation that boundaries move in several directions through the use of ICT. The second type of scenarios show that the nature of organizational boundaries is changing and that they are being redefined.

\subsection{Scenarios about the changing direction of organizational boundaries}

\section{Scenario I: The colonization of the environment by the focal organization}

In this scenario a government organization tries to reduce uncertainty about the speed, quantity and quality of the data which should be delivered by other organizations. An organization tries to formalize and discipline the exchange of data by extending its discretion. ICT is used as a way of colonizing the environment, especially the data exchange relations with certain groups. Very often formats and protocols are developed, which other organizations are obliged to use when they exchange data. Especially EDI technology favors this kind of colonization strategy. Moreover, developing formats and using EDI offers all kinds of efficiency advantages which in the end will lead to a further rationalization of the internal information processing processes.

For instance, when a garage inspects a used car on its safety -every car which is older than three years should be inspected every year - it is obliged to use a certain format to electronically exchange the relevant data with the Vehicle License Agency. Another example is the so-called SAGITTAnetwork of the Customs Administration. Companies which are active in the import of goods are obliged to pay taxes. An EDI-network which connects the Customs Administration and a large number of firms enables these firms to handle their taxes electronically. The result is that the boundaries of the Vehicle License Agency and the Customs Administration are being extended. They control the exchange of information by the garages and the import companies by introducing a data-architecture which standardizes the contents of data and data exchange and a communication-infrastructure which enable them to actually exchange the necessary information.

A number of factors favors this colonization scenario. First, there is the powerful position of the organizations in question. Very often these organizations have a well established position and reputation as a data administrator and registrar, like the Vehicle License Agency, the Tax and Customs Administration, the Land Registry and the Student Loans Agency. Their power is built on the fact that other organizations and people are legally obliged to exchange certain data and they have gained knowledge and experience in handling large amounts of data. Secondly, the most important characteristics of ICT which account for this scenario are the capability to facilitate massive transactions and to exercise control. Thirdly, in this scenario we see that a specific type of ICT is used. EDI and data formats are used to extend the boundaries of the organizations in question. Also the kind of data which is exchanged favors this scenario: it is rather stable, operational, quantitative and wellstructured, standardized data. The information relations are stable and have a rather intensive exchange character.

Looking at the models of organization I have described in section two, we see that this scenario can be understood from the rational-legal and systems and the institutional approach of organization. The rational approach stresses the importance of formalization as a way of reducing uncertainty and enhancing the rationality of the internal information processing processes. The open systems and institutional model stresses the importance of dependency, due to legal obligations to deliver certain data.

Scenario II: The penetration of the focal organization by the environment In this scenario we see the opposite. An organization can be penetrated by the environment thereby using ICT and confronting the focal organization with new and unknown forms of uncertainty. The boundaries become electronically permeable. If an organization lingers about whether its employees should have access to the Internet, the main question to be considered is very often, do we loose control? And what do these new forms of electronic communication mean for the traditional procedures for handling messages which an organization has developed to communicate with the outside-world? What is the status of an e-mail message? Can a citizen appeal to these messages if he/she has a legal dispute with the agency in question? 
If every employee has new forms of access, then he/she becomes a gatekeeper. This could be a threat to the more traditional gatekeepers. Their monopoly is being challenged. In a number of Dutch ministries, the question has been raised if a unit can have its own World-Wide Web page. Does this threaten the unity of the department? Or, is this a prerogative of the corporate communications and public relations unit? Moreover, if an individual unit opens its own page, what kind of information should be made accessible for outsiders?

The penetration of the organization by the environment is not only perceived as a threat. For instance, Dutch university libraries conceive the possibilities that the Internet offers in terms of access as a chance. Here we observe that the goals i.e. tasks of libraries, for instance enabling people to learn and a low threshold, is connected to certain values of the virtual culture of the Internet: free information and universal access. In this example the permeability of organizational boundaries can be seen from a cultural perspective. Also, it would be interesting to see if the position and status of those civil servants who participate in discussion groups - which are sometimes initiated by agencies to discuss policy proposals - changes. Is there is a tension between the horizontal culture(s) of the Internet and the hierarchical culture of the agency they belong to? An experiment in the Dutch province of Brabant shows that an active civil servant who participated in such a discussion group, was asked by his fellow-participants if he talked as a representative of the regional government. However, he had not the position to do so, nor was he able - because of the speed of the discussion - to consult his colleagues and/or superiors. In the end he was only capable of participating as a person without a formal title. We can observe a process of 'exclusion' out of the existing organization and a process of 'inclusion' in an new organization, the discussion platform.

Especially the 'unstructured' world of the Internet and the World Wide Web creates new sources of uncertainty, which are sometimes seen as opportunity or as a threat. If we look at relevant characteristics of ICT we see that communication and transparency are important characteristics that account for the penetration of organizations. If we look at the information relations and patterns which occur, than we see that unstructured data is exchanged. Very often organizations try to protect themselves to these new forms of uncertainty, by trying to establish all kinds of procedures to protect the stability of the organization and certain gatekeeper positions, which can be understood from the rational-legal and political model of the organization. Process of 'inclusion and exclusion' can be understood form the cultural model of the organization.

\section{Scenario III: The integration of organizations}

In this scenario the information between organizations is shared and exchanged in such a way, that organizations integrate or couple their information processing, planning and other working processes in order to further reduce uncertainty. This enhances the rationality of the organizations involved. Very often this integration takes place between organizations which are a member of the same valuechain. The electronic coupling of the links in the chain created new interdependencies between them. Sharing data in an electronic way means the further rationalizing of added value.

In the health sector we see that all kinds of electronic linkages are established between pharmacies, family doctors, hospitals, medical laboratories and nursing-homes. In several cities and regions in the Netherlands we see that local doctors and pharmacies in a region have developed a common data base to gain better insight in prescriptions. This system enables the pharmacists and doctors to see what kind of medication the patient had previously from another doctor or pharmacist. Enhancing the transparency of the patient and its medication leads to a better and more professional service delivery. At the same time in the city of Eindhoven, the Catharina Hospital has started some experiments with electronic communication between regional and the hospital's doctors. When a physician in a hospital has released a patient the necessary letter of release, containing vital medical information, is sent electronically to the family doctor. This has the advantage that the family doctor has a better and much quicker insight in the medical history of the patient and the hospital's treatment. Also laboratory results, like blood test results, are given electronically. Moreover, the planning processes between hospitals and nursing-homes are being coupled in certain regions. When a patient is released from hospital but he still needs professional medical care, which only a nursing-home can give him, one major question is: which nursing-home has the capability to nurse this patient? The coupling of capacity planning processes between hospitals and nursing-homes leads that the total capacity in a region has become more transparent, so that the coordination between demand and supply of nursing 
capacity has improved.

In the social security we see another kind of integration. The fight against abuse and fraud has lead to an increasing awareness about the nature and number of interdependencies between a number of public organizations with different but complementary tasks within this policy sector. This has led to the establishment of common information architecture and the development of a number of playing rules for exchanging data. The so-called RINIS concept tries to achieve procedural integration, thereby recognizing the autonomy and the ownership of certain data of the in RINIS participating organizations.

The observations raised in this scenario can for instance be understood from the perspective of interorganizational relations, in which exchange and interdependency are the key concepts. To what extent do organizations share the same data? May they alter the data? What does it mean for their autonomy? And in the example of the disclosure of the doctor's and pharmacist's prescriptions, how does it affect the professional behavior of doctors in terms intercollegial monitoring, which has also important cultural and political implications. At the same time the rational model of organizations can give some important insights why and to what extent organizational boundaries in this scenario are shifting. Developing interorganizational information systems and infrastructures can increase the rationality of the internal information processing and decision-making processes.

Looking at these and other examples we see that transparency and communication are the most important characteristics of ICT, which lead to more permeable organizational boundaries. Moreover, more transparency opens the door to more external control. However, control is a characteristic of ICT which always plays a role in the shaping of interorganizational relations.

The data which is exchanged has a rather stable and standardized character, because it relates very often to operational data. The information relations are also rather stable and formalized, which also influences the kind of ICT. EDI systems and common data infrastructures, like regional medical systems, are favored. We also see that formats and protocols are developed to facilitate a smoother exchange of data.

\subsection{Scenarios regarding the changing nature of organizational boundaries}

As mentioned before, organizational boundaries can change in several directions. However, this just one set of expectations. Another set deals with the changing nature of these boundaries.

\section{Scenario I: The blurring of organizational boundaries}

When organizations are electronically penetrated by the environment, or if organizations share information and integrate their operational and planning processes, we often see that boundaries begin to blur.

Boundary blurring can be understood from a cultural and the political model. If people from other organizations can look into certain information systems, this influences notions like awareness and interdependency. It influences the way of conceiving these people at the other end of the 'line', for instance in terms of 'Big Brother'. Does it lead to a surveillance culture? In the Dutch city of Rotterdam members of the district attorney's office have limited authorization to look at a select number of data in the operational systems of the regional police, which at a later stadium will be transferred to them on paper (the so-called record of evidence). The advantage is that the district attorney can subpoena a suspect more quickly. At the same time he easily can monitor the behavior of the attending police officer. This example underlines also the scenario of the colonization of the environment: the attorney's office can monitor the throughput of the police. Moreover it re-defines the boundaries between the executive power (the police) and the judiciary (district attorney's office). It challenges constitutional principles like the division of power and the idea of checks and balances.

Another example is the Dutch BVE network. This is an Internet and World Wide Web application. Using the Internet, a web has been spun over a large number of schools for educational training and adult education. Students are given access to the courses and educational material of other schools. Learning at a distance has become a real option. We also see that a web has been spun over the university libraries in the Netherlands. A student at Tilburg University can log into the files and catalogi of Utrecht University. The electronic linkages between the libraries and the schools have 
created a new organization, crossing the traditional and physical boundaries of these schools and libraries by making them obsolete. The notion of a class room is, for instance, fundamentally challenged. What we see here, is that transparency, communication and virtual reality are important characteristics of ICT. Especially Internet technology fundamentally challenges the idea of organizational boundaries.

\section{Scenario II: The fixation of organizational boundaries}

Organizations are afraid of external uncertainty which is mobilized by ICT. They try to protect their own autonomy by establishing fire-walls or buffers. Boundaries are being reinforced by using ICTapplications. The development of the so-called intranet is an example of this scenario. An intranet is a company-wide network which very often operates like the Internet, but has none or a limited amount of access to the outside world. Intra-nets aim at using the advantages of the Internet, in terms of email or accessibility of company-wide databases but, on the other hand, it tries to protect its users from 'bad' influences from outside. Do these outside connections seduce users to surf all day on the Internet and prevent them from doing their work? How far can an outsider enter the organization and use organization-owned information? Does he need special authorization procedures or code words? Are there within the organization special gatekeepers, who have privileged access to the Internet?

An example of a interorganizational intranet which connects separate public and private organizations and at the same time tries to protect its boundaries (this is sometimes called an extranet) is MIS, the Environmental Information Service System of the North Holland region. To some extent informational resources are shared between local and regional governments and private corporations, but citizens for which this information could also be interesting are not given access to this Web page. So certain groups are excluded and other are excluded as a way of protecting organizational boundaries.

The RINIS concept also shows us another way of preserving the informational autonomy of the participating organizations. A number of these organizations control certain registers. The data of these registers are recognized by the other RINIS organizations as authentic data bases. So the Tax and Customs Administration has the monopoly on the income information, the GBA system has the monopoly on name, address, place of living, date of birth information and the Vehicle and License Agency has the only authentic data on vehicles. Another way of protecting organizational boundaries is the automatic referal index of the RINIS system. If one organization ask certain data of an other organization this question is delt with by using a referal index. Certain questions are automatically transferred. Other questions get a special treatment, if they do not meet the specifications of the protocols. This index functions as an automatic gatekeeper.

The examples show how insights from for instance the rational-legal, the political and the institutional model organizations can be used to see how organizational boundaries are being reinforced.

\section{Scenario III: Controlled transparency}

Two or more organizations can agree to exchange information to a certain degree. In this scenario the previous two scenarios are combined. The degree in which organizations become transparent to each other is fixed within certain limits. Within a well-defined framework they become mutually transparent. However, if an organization wants to cross the frameworks boundaries, bells begin to go off. This means that only a limited number of data can be exchanged and used, or strict authorization has to be given to look into or use a database.

The case of the Student Loans Agency shows us that students are only able to a certain, welldefined and well-protected level to cross the boundaries of the agency. However, they are able to check and alter this limited number of standardized data (e.g. changing the period and number of return-payments), by using the smart cart technology which is distributed by the Student Loans Agency in combination with the communication terminals which are distributed among the universities. They are also able to ask questions, which will be answered in 24 hours. The Student Loans Agency shows that an organization can colonize its environment by re-designing the relations with the student and at the same time become more transparent for its clients. The boundaries of the Agency have become more permeable, but on the conditions set by the agency. This also influences the internal structure of the Agency. They are now establishing 'front offices'. These offices consists 
of multi-disciplinary teams which can handle almost all the questions raised, within one or two days. The controlled penetration of the outside world, which is made possible by ICT, leads to new ideas and values regarding client-friendliness within the Agency. Moreover these 'front offices' become important 'gatekeepers' because they have the monopoly of the communications with the outside world. The effectiveness and legitimacy of the Agency depends very much on these interactions.

So, to some degree organization boundaries become permeable, begin to blur, but a there is a borderline, which cannot be crossed. All kinds of procedures and firewalls are developed and introduced to protect the informational hart of the organization Very often privacy considerations or considerations of a strategic nature mark the informational domain which is not accessible for others. Moreover, one can protect this heart, if an organization or a coalition of organizations can determine the selection and use of ICT. Boundary changes can be understood from the interorganziational model of organizations (focusing on the external control of organizations), the rational-legal (focusing on the internal structure and the organization's procedures) and the cultural model (referring to changing values and norms in the approach of clients).

\section{The management of organizational boundaries and changing organizational jurisdictions: an institutional perspective}

\section{Organizational boundaries and jurisdictions on the move}

The redefinition of information exchange relations between government organizations and their environments - suppliers and clients - by using ICT implies that uncertainty can be reduced but at the same time that new forms of uncertainty are being introduced, which influence the stability and the autonomy of the organization. Network technology opens 'literally' new horizons. Boundaries are going to change. They are on the move. We have seen that environments are being colonized, that organizations are being penetrated by the outside-world, and that organizations integrate.

Organizational boundaries begin to blur, fully or to some extent, or they are being protected by new walls. Therefore, the management of organizational boundaries is an important strategic issue because it influences the definition of organizational jurisdictions. Some jurisdictions become more powerful and dominant, while other shrink or integrate. This raises the question if the original description and allocation of certain tasks and competencies still matches with these changing organizational boundaries and jurisdictions and the corresponding changes in the distribution of power among them. Checks and balances are being challenged, while perhaps new checks and balances are being created which do not correspond with well-established principles of the legal system. In this section I will show how these changing boundaries influence some elements in the definition of organizational jurisdiction.

\section{Exclusive authority of an actor as a unified entity}

The sharing of information and knowledge between government organizations imply that organizational boundaries (partially) begin to blur. This can influence the exclusiveness of a certain authority. We can see this in the creation of integrated 'front offices' which try to deliver public services to citizens as a 'whole person'. However, there is a gap between the authority of these front offices and the authority of the 'back offices' which feed these front offices with information. These back offices have a well-defined organizational jurisdictions. They have exclusive competencies, but in the 'front office' these competencies are being shared and integrated. This also influences the way in which these front offices and back offices are accountable for their actions an decisions. I will elaborate later on this point.

Other examples are the websites of certain units within a government agency and the e-mail facilities for civil servants. As said before, the fact that these units are able to develop their own web sites are often seen as a threat for the unity of an organization. What is the status of the information of these units? Who is political responsible for them? Should there be some degree of central coordination? What is the status of an e-mail message if a civil servant participates in a discussion platform on the Internet, or if he answers to questions of citizens? E-mail is often seen as a 'slippery' way of communicating which enables civil servants to place themselves outside the control of the organization. 


\section{Legal and political accountability}

The changing of he boundaries of government organizations and the entanglement of informational domains can lead to difficulties in exercising political and public control. I can illustrate this problem by referring to the establishment of civic service centers or one-stop shops within a municipality. There can be a tension between the responsibility for the integrated front office and the responsibility for the separate back office organizations. Who can be hold responsible if the front office organization takes decisions towards its clients, if this information is unjust and incomplete and it is not quite clear if this is the results of faults in the databases of the back offices? When informational domains entangle, it is quite difficult to find out where something has going wrong; certainly is the original data has been adapted. And if information is shared, where lies the right of ownership? Who is responsible if a new data is being created on the basis of the data given by the back offices? Who is responsible for the creation of new, virtual databases?

Accountability is enhanced if there are 'checks and balances' between organizations in order to prevent abuse of informational power. From the perspective of improving customer friendliness or attacking fraud a better insight in developments in a policy sector or target group, the integration of information systems and the sharing of information can be defended. The blurring of organizational boundaries is then a necessary consequence. However, this raises some questions which do not only related to the privacy aspect, but also to the distribution and concentration of informational power. The extension (i.e. colonization) and integration of informational domains of government organizations has not been an issue which raised a lot of public and political attention. It is a process which has passed very silently. It is an issue which is being discussed and dominated by civil servants and the bureaucracy. The notion of 'checks and balances' as a principle in (re)designing information relations in order to neutralize concentration of informational power does not play an important role in political and public discussions. Interorganizational information systems and data sharing have been primarily seen as an instrument to enhance the rationality of policy formulation, implementation and monitoring (Bekkers, 1993; Van de Donk, 1996).

However, in several political theories the existence of organizational boundaries play an important role as a way of creating 'checks and balances' in order to protect an undesired degree of power in the hand of one or a limited number of people and organizations. That it is possible to develop a common information architecture between organizations, which respects the autonomy and the 'checks and balances' between them is shown by the RINIS concept. In RINIS there is the agreement that the ownership of certain data is being protected. If an organization wants to use certain data which is gathered and owned by other organizations, it does not collect the data themselves, but it asks (by an automated reference index) if it may use this data. The tax administration has the monopoly on income information, while the municipalities have the monopoly on the right data with respect to name, address, place and time of birth etc. However, in the construction of RINIS no attention is paid to introducing ' checks and balances' in the relationship between the informational power of the participating organizations and the citizen.

\section{To determine rights and obligations of citizens in a task domain}

The fact that organizational boundaries begin to blur, or that boundaries are being enlarged and environments are being colonized through ICT changes the position of the citizen vis à vis government and its informational rights and obligations. For instance, the coupling of databases means that more and more information is being gathered about a citizen, while he has never given his permission to combine these data and use the information created. He has only given his permission to use data for certain specific goals. The informational autonomy of citizens to determine how data is being used, is challenged. Moreover, we see that through ICT a citizen is electronically linked with public administration. He becomes more an more a part of public administration. He is not seen as a autonomous individual, but as an information providing agent. The handling of data by this agent is controlled and monitored in order to reduce uncertainty and increase the efficiency of internal processes. From a more democratic and legal perspective one can argue that the boundaries between a government organization and the citizen can be seen as a safeguard against abuse of power, as way of creating 'checks and balances'. These walls are fallen down when a citizen is included in the organization of public administration. 


\section{A certain degree of discretion}

The electronic integration of organizations (e.g. the example of RINIS) and the electronic colonization of organizations also influence the discretion of organizations and citizens (e.g. the example of the Vehicle License Agency). Both scenarios point in the direction of Zuurmonds (1994) infocracy. Typical of infocracy is the increased standardization of data definitions and exchange relations, and corresponding procedures and routines. The organization or coalition of organizations who can develop and impose a common data architecture which can influence the degree of discretion of other organizations. If these organizations or even citizens want to exchange information they have to comply with the data definitions etc. of the data architecture. Developing and imposing a data architecture means that an organization of coalition of organizations can influence the decisionmaking premises of the gathering and use of information by other organizations and citizens (Zuurmond \& Snellen, 1997). According to Pfeffer and Salancik (1978) organizational boundaries are going to move, if one is capable to alter and influence these decision making premises.

However, the degree of discretion can also change in another way. The line of reasoning above implies that the discretion of organizations and citizens is being limited. ICT, especially network technology like the Internet, can also increase the discretion of the participants in the network. If a member of organization participates in a discussion group or platform on the Internet, he becomes part of virtual community. The formal background of the participant becomes less important and his discretion enlarges to act according his own wishes as the example of the civil servant of the Dutch province of Brabant who participated in a discussion group, illustrates.

\section{Multi-dimensional organizational jurisdictions and the management of boundaries} Organizational boundaries are an important indication for organizational jurisdiction. ICT can alter both of them. However, it is important to notice that organizational jurisdiction should not be limited to a narrow legal definition. The competencies of an organization affects also the cultural and political contents of an organization. It gives meaning to people and it enables certain people to exercise power within an organization. Moreover, organizational jurisdictions also influence the exchange relations with other organizations. Some competencies can only be exercised if other organizations provide vital information. I can illustrate this with an example. In this Student Loans Agency the call center and help desk has been transformed to a professional front office. Within the near future the communication with students will be handled electronically for more than $75 \%$. This has important consequences for the culture and the management of the front office, in contrast to the traditional administrative back offices. Certain values which play an important role in the back office can differ and clash with those in the back office, while both offices are situated in the same organization. The front office is necessarily more open for influences from the environment than the back office, because they have a closer relationship with the students. Moreover the front office is team-oriented, client-oriented, technology-driven and has a problem-solving orientation, while the back office has a more bureaucratic and functional orientation. In the end the division between front office and back office can lead to a shift in power between them.

This example shows that the management of boundaries takes places in several organizational spheres or domains. Redesigning external relationships leads to changing organizational boundaries, but these changes have also important consequences for organizational culture and politics. This means that processes of boundary management takes place in several organizational spheres or domains, which can conflict.

Wanted: a political theory of government in the information age The scenarios and examples as described in this chapter show that organizational boundaries are changing. In general, we see at the one hand that boundaries are enlarged and thus the control potential of government organizations; on the other hand we see that boundaries begin to blur. On a micro level, studying the specifics effect of ICT applications these changes look maybe harmless, but they have profound implications on a meso and macro level. These changes also influence the definition of the jurisdiction of organizations. Well-established patterns of responsibility and accountability as well as the distribution of powers between these organizations are drifting. In the end 
they also affect the relationship between government and the citizen. The ideas and principles which lay behind these patterns had their meaning in an age in which there was no computer technology. If Montesquieu and Madison would live at the beginning of the 21th century, how should they appreciate these changes? It 250 years ago that Montesquieu wrote his famous ' $L$ 'esprit de lois' and about 200 years ago that Madison drafted 'The Federalist Papers', but how fruitful are the principles of the division of power and 'checks and balances' in the age of computer and network technology? The changing boundaries and jurisdictions through the use of network technology asks for a re-definition of the roles of government and the citizen in the information age.

[1] Prof. Dr. Victor J.J.M. Bekkers is professor of information and communication technology infrastructures in the private and public sector at the Erasmus University Rotterdam. He is also a member of the management consultancy division of CMG Public Sector B.V. in The Hague.

\section{Literature}

Adams, J.S. (1980) Interorganizational processes and organization boundary activities, in: Staw, B.J. and G.R. Salancik (eds.), Research in organizational behavior, vol. 2, 321-355. Greenwich CN:JAI

Press, pp. 321-355.

Aldrich, H. (1979), Organizations and environments. Englewood Cliff: Prentice Hall.

Barret S. and B. Konsynski (1982) Interorganizational information sharing systems, in:. MIS Quaterly Special Issue, nr. 6, pp. 93-104.

Bekkers, V.J.J.M. (1993), Nieuwe vormen van sturing en informatisering. Delft: Eburon.

Bekkers, V.J.J.M. (1998), Grenzeloze overheid. Over ICT en grensveranderingen in het openbaar bestuur. Alphen aan de Rijn: Samson.

Bekkers, V.J.J.M., Wiring public organization and changing organizational boundaries, in: Snellen, I.Th.M. \& W.B.J.H. van de Donk (eds.) (1998)., Public administration in the information age.

Amsterdam/Berlin/Oxford/Tokyo/Washington: IOS, pp. 57-78.

Benson, J.K. (1975) , The interorganizational network as a political economy, in:Administrative Science Quaterly vol. 20, pp. 229-249.

Burkens M.C. et al (1997), Beginselen van de democratische rechtsstaat, Deventer: W.E.J. Tjeenk Willink.

Crozier, M. and E. Friedberg (1980), Actors and systems. Chicago: Chicago University Press.

Donk, W.B.J.H. van de, De schema in arena, Lelystad: Vermande.

Easton, D. (1965), A framework for political analysis. Englewood Cliffs: Prentice Hall

Evan, W.M. (1966), The organization-set: towards a theory of interorganizational relations, in:

Thompson, J. (ed.), Approaches to organizational design. Pittsburg: Pittsburg University Press.

Frissen, P.H.A. (1989), Bureaucratische cultuur en informatisering. Den Haag: SDU.

Frissen, P.H.A. (1996), De virtuele staat. Schoonhoven: Academic Press.

Haas, J.E. and Th.E. Drabek (1973), Complex organizations. New York/London MacMillan

Katz, D. and R.L. Kahn (1966), The social psychology of organization. NewYork/London:Wiley.

Kerckhove, de D. (1996), Gekoppelde intelligentie. Epe: SMO

Levine, S. and P.E. White (1961), Exchange as a conceptual framework for the study of interorganizational relationships, in: Administrative Science Quaterly., vol 5, pp. 583-601.

Marret, C.B. (1971), On the specification of interorganizational dimensions, in: Sociology and Social Research, vol. 56, pp. 83-99.

Miller, E.J. and A.K. Rice (1967), Systems of organization. London/New York: Tavistock Mintzberg, H. (1979), The structuring of organization. Englewood Cliffs:Prentice Hall.

Morgan, G.A.(1986), Images of organization. London/Beverly Hills/New Dehli: Sage

Pfeffer, G. (1981), Power in organizations. Cambridge Mass: Ballinger.

Pfeffer, G. and G.R. Salancik (1978), The external control of organization. New York: Harper \& Row.

Picot, A., R. Reichwald and R. Wigand (1995), Die grenzenloze Unternehmunng. Wiesbaden:Gabler Robins, J.A. (1987), Organizational economics: Notes on the use of transaction-cost theory in the study of organization, in: Adminsitrative Science Quaterly, vol. 32, pp. 68-86.

Scott, W.R. (1992), Organizations. Newbury Park/London/New Dehli; Prentice Hall. 
Scott, W.R. (1995), Institutions and organizations. Thousand Oaks/London/New Dehli: Sage.

Thompson, J.D. (1962) Organizations and output transactions, in: American Journal of Sociology, vol. 68, nr.3, pp.309-324.

Thompson, J.D. (1967), Organizations in action. New York: McGraw Hill.

Van de Ven, A.H., G. Walker and Liston (1979), Coordination patterns within an interorganizational network, in: Human Relations vol. 32, nr.1, pp. 19-36.

Warren, R.L. (1967), The interorganizational field as a focus for investigation, in: Administrative Science Quaterly, vol. 12, pp. 396-419.

Weick, K.E. (1969), The social psychology of organizing, Reading Mass: Addison-Wesley.

Willke, H. (1992), Systemtheorie. Frankfurt a/M/New York: Fischer

Zucker, L.G., M.R. Darby, M.B. Brewer and Y. Peng (1995), Collaboration structure and information dilemmas in biotechnology: organizational boundaries as trust production. National Bureau of Economic Research.Working Paper, Cambridge Mass.

Zuurmond, A. (1994), De infocratie, Rotterdam: Phaedrus

Zuurmond, A. \& I.Th.M. Snellen (1997), From Bureaucracy to infocracy, in: Taylor, J.A., I.Th.M.

Snellen \& A. Zuurmond, Beyond BPR in public administration. Amsterdam: IOS Press: 205-224. 